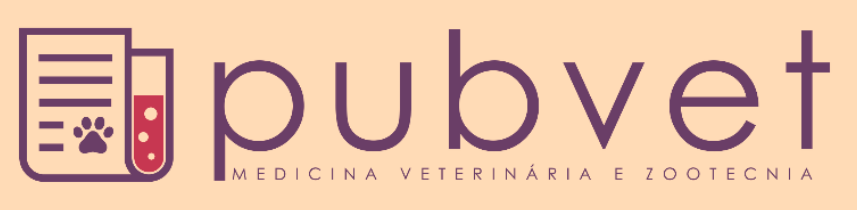

https://doi.org/10.31533/pubvet.v13n5a324.1-4

\title{
Nefrocalcinose medular bilateral por ingestão de Zantedeschia aethiopica (copo de leite) em filhote canino: Relato de caso
}

\author{
Rayzza Rodrigues Perin ${ }^{1}$, Dina Regis Recaldes Rodrigues Argeropulos Aquino ${ }^{\circ}$ \\ ${ }^{1}$ Aprimoranda em clínica e cirurgia de pequenos animais, Clínica Veterinária da UNIDERP/Anhanguera Agrárias. Campo Grande-MS Brasil. \\ ${ }^{2}$ Professora do Curso de Medicina Veterinária UNIDERP/Anhanguera, Campo Grande - MS Brasil. \\ *Autor para correspondência, E-mail: rayzzaperin@gmail.com
}

\begin{abstract}
Resumo. A planta ornamental Zantedeschia aethiopica, vulgarmente conhecida como "copo-de-leite", contém idioblastos de oxalato de cálcio em sua lâmina foliar, pecíolo e espata. Este componente é tóxico para o organismo e pode ocasionar distúrbios gastrointestinais, renais e hepáticos, sendo os sinais clínicos variáveis e o diagnóstico baseado principalmente em histórico de ingestão acidental da planta. Uma das alterações que podem ser encontradas nesses casos é a presença desses cristais de oxalato nos rins, gerando uma nefrocalcinose. O objetivo deste trabalho foi de relatar uma ocorrência de nefrocalcinose medular por ingestão de Zantedeschia aethiopica em um filhote canino.
\end{abstract}

Palavras chave: alteração renal, calcificação, filhote, intoxicação por planta, Zantedeschia aethiopica

\section{Bilateral bone marrow nephrocalcinosis due to ingestion of Zantedeschia aethiopica (cup of milk) in canine pups: Case report}

\begin{abstract}
The ornamental plant Zantedeschia aethiopica, commonly known as "milk cup", contains calcium oxalate idioblasts in its leaf blade, petiole and spathe. This component is toxic to the body and may cause gastrointestinal, renal and hepatic disorders, with clinical signs being variable and the diagnosis based mainly on the history of accidental ingestion of the plant. One of the alterations that can be found in these cases is the presence of these crystals of oxalate in the kidneys, generating a nefrocalcinosis. The objective of this work was to report an occurrence of spinal cord nephrocalcinosis by ingestion of Zantedeschia aethiopica in a canine puppy.
\end{abstract}

Keywords: kidney change, calcifications, puppy, plant poisoning, Zantedeschia aethiopica

\section{Nefrocalcinosis medular bilateral por ingestión de Zantedeschia aethiopica (cartucho) en cachorro canino: Relato de caso}

Resumen. La planta ornamental Zantedeschia aethiopica, comúnmente conocida como "cartucho", contiene idioblastos de oxalato de calcio en su lámina foliar, pecíolo y espata. Este componente es tóxico para el organismo y puede ocasionar disturbios gastrointestinales, renales y hepáticos, siendo los signos clínicos variables y el diagnóstico basado principalmente en histórico de ingestión accidental de la planta. Una de las alteraciones que se pueden encontrar en estos casos es la presencia de estos cristales de oxalato en los riñones, generando una nefrocalcinosis. El objetivo de este trabajo fue de relatar una ocurrencia de nefrocalcinosis medular por ingestión de Zantedeschia aethiopica en un cachorro canino.

Palabras clave: Alteración renal, calcificaciones perro, intoxicación por planta, Zantedeschia aethiopica 


\section{Introdução}

Segundo Evenepoel et al. (2014), a nefrocalcinose ocorre devido a desordens no metabolismo de minerais que geram deposição de fosfato de cálcio nos rins, em casos de hipercalcemia ou hiperfosfatemia. Este achado é de extrema importância, pois a constante deposição deste componente gera resposta inflamatória e dano renal progressivo. Dentre as alterações que podem levar à hipercalcemia e posteriormente à nefrocalcinose, estão: hiperparatireoidismo primário, hipoadrenocorticismo, insuficiência renal, lesões ósseas, hipercalcemia humoral de malignidade, hipervitaminose D, hipercalciúria idiopática e hipotermia grave (Cahua \& Perales, 2018; Evenepoel et al., 2014; Rejnmark et al., 2011; Soriano, 2002).

Estudos de Rocha et al. (2006) demonstram que o copo-de-leite (Zantedeschia aethiopica) apresenta idioblastos com cristais de oxalato de cálcio na lâmina foliar, pecíolo e espata, assim como de Oliveira \& Pasin (2017) comprovaram que as begônias (Begonia sp.) apresentam oxalato de cálcio no caule. Relatos de Giese et al. (2015) identificaram intoxicação por comigo-ninguém-pode (Dieffenbachia picta Schott), onde foi possível comprovar lesões renais provocadas pelos cristais de oxalato de cálcio solúveis, lesões gastrointestinais provocadas pelos cristais de oxalato de cálcio insolúveis, e lesões hepáticas provocadas pelos próprios cristais de oxalato.

Segundo Nelson \& Couto (2015) devem ser solicitados para verificação da existência de sequestro de cálcio ósseo ou mineralização de órgãos: dosagens de cálcio ionizado (fração biologicamente ativa do cálcio total sérico), e fósforo a fim de identificar o nível de alteração por hipercalcemia ou hiperfosfatemia e as dosagens de PTH (paratormônio) e PTH-rp (proteína ligada ao paratormônio) para identificar ou descartar hiperparatireoidismo primário e hipercalcemia humoral de malignidade. $\mathrm{O}$ diagnóstico de nefrocalcinose pela intoxicação por oxalato de cálcio proveniente Zantedeschia aethiopica, "copo-de-leite", teve como fundamentação dados de anamnese cedidas pelo tutor e as manifestações clínicas, associados aos resultados dos exames complementares. No exame ultrassonográfico foram observadas alterações renais e o diagnóstico foi de calcificação renal difusa bilateral, nefrocalcinose.

\section{Material e métodos}

Foi atendida na Clínica Veterinária da Uniderp, a paciente da espécie canina, fêmea, SRD (sem raça definida), três meses de idade, $1,45 \mathrm{~kg}$, boa condição corporal, com histórico de êmese, diarreia, prurido anal, apatia, hipodipsia e disfagia. A tutora revelou que o animal tinha histórico de parorexia, ingestão de objetos e plantas (flores e folhas). Na noite anterior ao surgimento dos sinais clínicos havia ingerido uma planta na residência que não foi identificada. A proprietária citou algumas espécies das plantas que cultiva e, dentre elas, foram identificadas algumas tóxicas como a rosa do deserto (Adenium obesum), o copo de leite (Zantedeschia aethiopica) e a begônia (Begonia sp.). Durante exame físico foram identificadas as alterações: apatia, leve desidratação e mucosa oral hipocorada. Foram realizados os exames ultrassonográfico, hemograma, urinálise e análise bioquímica. $\mathrm{O}$ animal permaneceu internado para tratamento de suporte até melhora do quadro clínico. Diante dos resultados dos exames complementares e o paciente apresentar quadro clínico sugestivo de intoxicação por ingestão de planta, foram solicitados como auxílio diagnóstico: imagens de raio X e dosagem sanguínea de cálcio, fósforo, PTH e PTH-rp. Estes exames foram recusados pela tutora devido ao alto custo.

\section{Resultados}

O exame ultrassonográfico revelou em alças intestinais: conteúdo luminal anecóico indicando enterite, no baço, esplenomegalia e hipoecogenicidade. Não foram encontradas alterações na tireoide e paratireoide. Pelo exame, foi constatada lesão renal que mostrou limite corticomedular alterado, córtex hipoecogênico, zona medular hiperecogênica indicando calcificação renal difusa bilateral (Figura 1). O diagnóstico foi de nefrocalcinose medular bilateral.

No resultado do hemograma foram observadas as alterações: policitemia, intensa trombocitopenia, leve leucopenia, com neutropenia, eosinopenia e linfopenia. A análise do perfil bioquímico revelou aumento dos valores da enzima ALT, sendo o valor máximo 102 e a alteração elevou a 359. A urinálise revelou cristais de oxalato de cálcio, urobilinogênio e cetonas. 


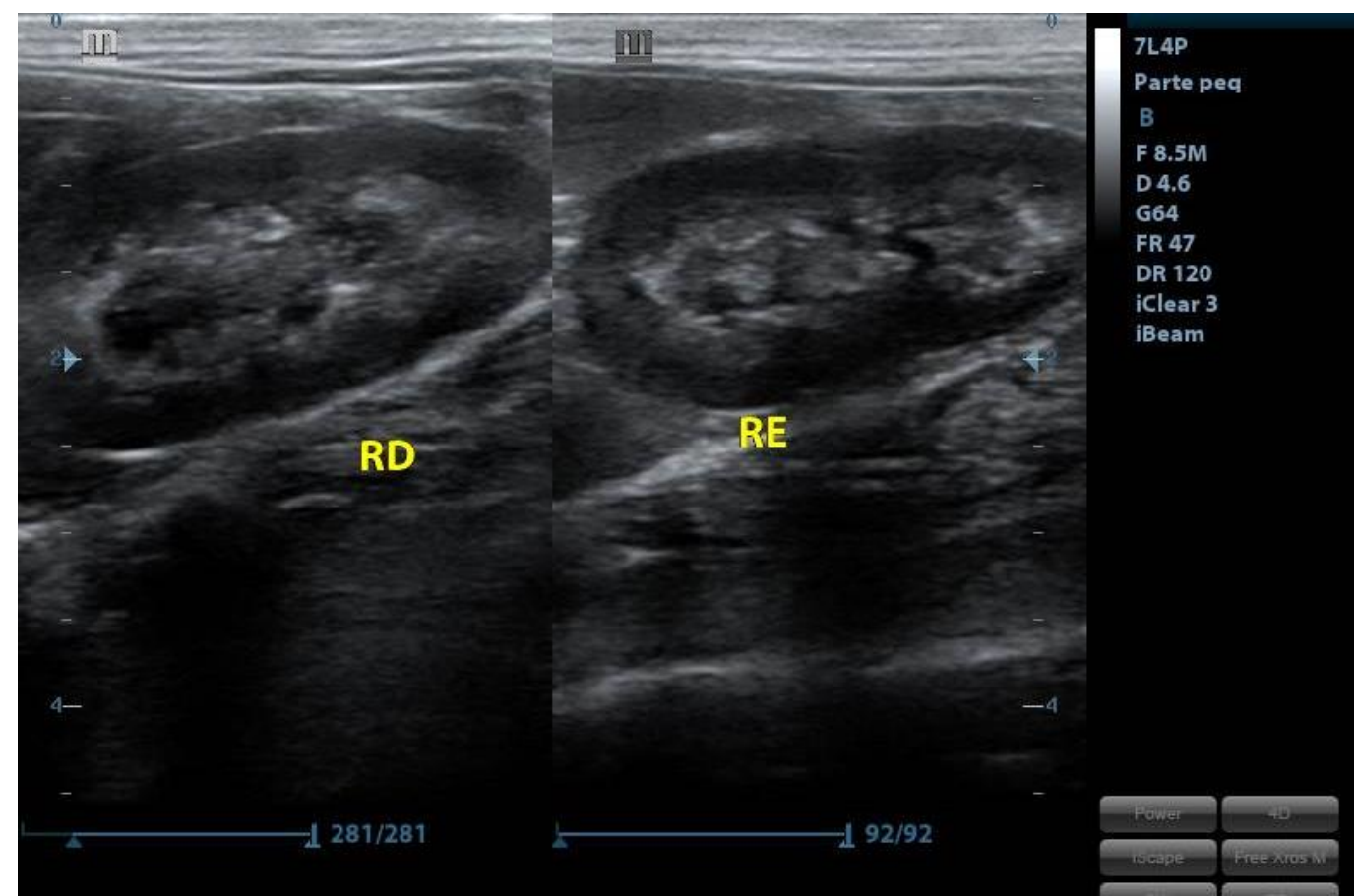

Figura 1. Ultrassonografia renal mostrando aumento difuso da ecogenicidade medular bilateral compatível com nefrocalcinose.

\section{Discussão}

O achado ultrassonográfico revelou uma nefrocalcinose bilateral e a urinálise mostrou excreção de cristais de oxalato de cálcio. O diagnóstico presuntivo foi calcificação renal difusa bilateral por ingestão da planta tóxica copo de leite (Zantedeschia aethiopica); que segundo Rocha et al. (2006), contém idioblastos de oxalato de cálcio na lâmina foliar, pecíolo e espata, que são tóxicos para o organismo, que resultam em hiperoxalúria, com aumento da absorção intestinal de oxalatos ou por intoxicação exógena por oxalatos ou seus precursores. Esses cristais de oxalato de cálcio foram descritos por Giese et al. (2015) em uma intoxicação por Dieffenbachia picta Schott (comigo ninguém pode), onde foi possível comprovar lesões renais provocadas pelos cristais de oxalato de cálcio solúveis, lesões gastrointestinais provocadas pelos cristais de oxalato de cálcio insolúveis, e lesões hepáticas provocadas pelos próprios cristais de oxalato.

$\mathrm{O}$ animal em estudo manifestou êmese, diarreia, prurido anal, hipodipsia e disfagia que remetem a própria irritação causada pelos idioblastos de oxalato de cálcio em contato com as mucosas. Conforme estudos de Rocha et al. (2006) esse contato com a mucosa oral pode gerar dor na deglutição e consequentemente disfagia e hipodipsia. Neste caso o paciente apresentou um quadro semelhante pela irritação da mucosa gastrointestinal. A elevação dos níveis de ALT e a enterite ocorrem pela injúria celular provocada pelos cristais de oxalato de cálcio insolúveis que lesionam células do tecido digestivo e hepático (Cumpston et al., 2003). A injúria renal pode também ter como causa o estresse oxidativo, devido à toxicidade do oxalato de cálcio (Davalos et al., 2010).

A espécie vegetal identificada como rosa do deserto (Adenium sp.) ou lírio-impala, que pertence à família Apocinaceae, originária do Sul da África e a Península Arábica, possui uma a seiva tóxica presente em suas raízes e caules, no continente Africano é usada como veneno das flechas para a caça, a seiva tóxica extraída após cozimento provoca sintomas respiratórios asfixiantes (Oliveira \& Pasin, 2017). Na outra espécie, begônia (Begonia sp.), a toxicidade estaria na ingestão do caule e da raiz desta, não comprovado o potencial tóxico em estudos realizados por Oliveira \& Pasin (2017). Foi relatado que o canino em estudo tinha acesso livre às plantas Adenium sp. e Begonia sp. identificadas como tóxicas; porém, não foram objetos de suspeita clínica porque não se assemelham ao histórico clínico ou à sintomatologia apresentada neste relato (Oliveira \& Pasin, 2017).

Ocorreu uma associação positiva entre os sinais clínicos apresentados pelo animal do presente relato e a toxicidade, patogenia e sintomas causados por esta espécie vegetal. Diante do relato e das alterações 
identificadas pelos exames complementares, o diagnóstico do animal do presente estudo foi sugestivo de nefrocalcinose medular bilateral pela ingestão da espécie Zantedeschia aethiopica (copo de leite), planta tóxica que contém cristais de oxalato de cálcio em suas estruturas.

\section{Conclusão}

Em pequenos animais é difícil de ser diagnosticada a intoxicação, aguda ou crônica, causada por plantas e também estabelecer a associação entre os sintomas e a ingestão. $\mathrm{O}$ enriquecimento ambiental e a atividade física são de extrema importância para o bem-estar animal, evitando muitos comportamentos estereotipados como a parorexia vista neste caso. Um ambiente enriquecido com brinquedos, comida, ou qualquer objeto interessante para o animal, impede o estresse que precede este tipo de hábito, sendo, portanto, indicado para prevenção da ingestão acidental de plantas tóxicas.

\section{Referências bibliográficas}

Cahua, J. \& Perales, R. (2018). Nefrocalcinosis intersticial y glomerulonefritis crónica en una perra. Revista de Investigaciones Veterinarias del Perú, 29(3):1065-1071.

Cumpston, K. L., Vogel, S. N., Leikin, J. B. \& Erickson, T. B. (2003). Acute airway compromise after brief exposure to a Dieffenbachia plant. The Journal of Emergency Medicine, 25(4):391-397.

Davalos, M., Konno, S., Eshghi, M. \& Choudhury, M. (2010). First Prize (Tie): oxidative renal cell injury induced by calcium oxalate crystal and renoprotection with antioxidants: a possible role of oxidative stress in nephrolithiasis. Journal of Endourology, 24(3):339-345.

Evenepoel, P., Cooper, K., Holdaas, H., Messa, P., Mourad, G., Olgaard, K., .. . Torregrosa, J. V. (2014). A randomized study evaluating cinacalcet to treat hypercalcemia in renal transplant recipients with persistent hyperparathyroidism. American Journal of Transplantation, 14(11):2545-2555.

Giese, B. G., Flofres, V. H., Bernardes, L. G. S., Moura, L. S., Marinho, R. H. F. P. \& Bittencourt, M. (2015). Intoxicação por ingestão recorrente de Dieffenbachia picta Schott (comigo-ninguém-pode) em um canino - relato de caso, Anclivepa.

Nelson, R. W. \& Couto, C. G. (2015). Medicina interna de pequenos animais. Amsterdan: Elsevier Editora.

Oliveira, R. R. \& Pasin, L. A. A. P. (2017). Ocorrência de oxalato de cálcio em diferentes espécies vegetais de uso ornamental. Revista de Ciências Ambientais, 11(3):41-52.

Rejnmark, L., Vestergaard, P. \& Mosekilde, L. (2011). Nephrolithiasis and renal calcifications in primary hyperparathyroidism. The Journal of Clinical Endocrinology \& Metabolism, 96(8):23772385.

Rocha, L. D., Pegorini, F. \& Maranho, L. T. (2006). Organização estrutural e localização das estruturas tóxicas em comigo-ninguém-pode (Dieffenbachia picta (L.) Shott) e copo-de-leite (Zantedeschia aethiopica (L.) Spreng). Revista Unicenp de Biologia e Saúde, 254-63.

Soriano, J. R. (2002). Renal tubular acidosis: the clinical entity. Journal of the American Society of Nephrology, 13(8):2160-2170.

Recebido: 25 de fevereiro, 2019

Aprovado: 15 de março, 2019.

Publicado: 21 de maio, 2019.

Licenciamento: Este artigo é publicado na modalidade Acesso Aberto sob a licença Creative Commons Atribuição 4.0 (CC-BY 4.0), a qual permite uso irrestrito, distribuição, reprodução em qualquer meio, desde que o autor e a fonte sejam devidamente creditados. 